Doi: $\underline{\text { dx.doi.org/10.17921/2525-5320.2016.27-33 }}$

\title{
INDICATIVOS DA FREQUÊNCIA NO USO DE ESTRATÉGIAS DE APRENDIZAGEM POR ALUNOS INGRESSANTES DE UM CURSO DE PEDAGOGIA
}

\author{
Ludimila Alves da Silva* - UEL
}

Paula Mariza Zedu Alliprandi** - UEL

Palavras-chave: Teoria do Processamento da Informação. Estratégias de Aprendizagem. Ensino Superior.

\section{INTRODUÇÃO}

O presente trabalho apresenta resultados parciais do Trabalho de Conclusão de Curso apresentado junto ao Curso de Pedagogia da Instituição Pesquisada. Está embasado teoricamente na Psicologia Cognitiva/Teoria do Processamento da Informação; em especial, ao uso de estratégias de aprendizagem, uma vez que, após leituras realizadas sobre o tema, foi possível perceber a importância das estratégias de aprendizagem para o "aprender a aprender", o que possibilita ao aluno ter o conhecimento de como ele aprende e quais as estratégias que o levam a compreender melhor determinado conteúdo.

Para Boruchovitch (1999), os indivíduos devem ser capazes de irem além do conhecimento factual em direção ao desenvolvimento de uma capacidade de pensar sobre os próprios pensamentos, ou seja: o indivíduo deve fazer uso da metacognição - conhecer o seu próprio conhecimento, saber quais seus modos de aprender e como fazê-lo para o desenvolvimento pessoal. Assim vê-se necessário o uso de estratégias de aprendizagem, como, por exemplo: grifar textos, ler o mesmo texto mais de uma vez, levantar perguntas acerca de uma leitura, dentre outras.

Segundo Dembo (1988 apud ALMEIDA, 2002), metacognição refere-se ao conhecimento dos próprios processos de conhecer, num planejamento, predição e monitoramento do próprio processo de aprender. Dessa maneira, percebe-se que o aluno que faz uso de estratégias de aprendizagem é autorregulado, sabe quais as estratégias que o levarão à aprendizagem e compreende também qual a maneira

\footnotetext{
*E-mail: ludimilsilva01@gmail.com

** E-mail: paulaalliprandini@gmail.com
} 
mais adequada para colocá-las em prática. Nesse sentido, é importante destacar a relevância das estratégias de aprendizagem no processo de pensar e ser capaz de aprender.

Sabe-se que todos usam estratégias de aprendizagem, por mais simples que elas sejam - como, por exemplo, reler um texto. Segundo Boruchovitch (1999), as estratégias de aprendizagem podem ser qualquer procedimento adotado para executar uma estipulada tarefa. Porém, segundo a Teoria do Processamento da Informação, quanto mais nova a informação recebida for trabalhada pelo indivíduo,maisela será entendida e se fixará nos esquemas já existentes, tornandose, assim, uma informação permanente. Portanto, o uso de estratégias de aprendizagem é considerado de grande importância para o "aprender a aprender".

O presente trabalho teve como objetivo geral analisar a frequência do uso de estratégias de aprendizagem por alunos matriculados nas 1as séries dos períodos matutino e noturno do Curso de Pedagogia de uma Instituição Pública do Paraná, como também verificar se há diferenças entre a frequência no uso de estratégias de aprendizagem entre os alunos dos períodos matutino e noturno.

\section{MATERIAL E MÉTODOS}

Participaram desta pesquisa 98 alunos matriculados na $1^{\mathrm{a}}$. série do Curso de Pedagogia, sendo 5 do sexo masculino e 93 do sexo feminino. Os participantes estavam subdivididos da seguinte forma, sendo: 31 alunos da turma 1000, 27 da turma 2000,20 da turma 3000, e também 20 alunos da turma 4000.

As turmas 1000e 2000 são ofertadas no período noturno e a as 3000 e 4000, no período matutino.

Para a coleta de dados foi utilizada a Escala de Avaliação de Estratégias de Aprendizagem, desenvolvida e validada por Santos e Boruchovitch (2015). Esta escala de estratégia de aprendizagem contém36 questões, sendo 35 de múltipla escolha, podendo ser respondida com as opções: sempre, às vezes, raramente e nunca. De acordo com a proposta da escala, foi atribuído o valor de 1 a 4 para as respostas, conforme segue: (sempre - 4 , às vezes- 3 , raramente -2 e nunca -1 ), permitindo analisar a frequência do uso de estratégias de aprendizagem. A questão 36 é considerada opcional, sendo respondida apenas se o participante usar outra estratégia de aprendizagem que não foi contemplada nas questões anteriores para possibilitar um enriquecimento da pesquisa. 
A escala é composta por 3 fatores subdivididos em: Fator 1- Autorregulação Cognitiva e Metacognitiva, Fator 2- Autorregulação dos Recursos Internos e Contextuais e Fator 3- Autorregulação Social.

Inicialmente, o projeto de pesquisa foi encaminhado ao Colegiado do Curso de Graduação em Pedagogia para a devida autorização da realização da presente pesquisa. Após a autorização do Colegiado do Curso de Pedagogia, o projeto tramitou junto ao Comitê de Ética, envolvendo Seres Humanos (CEP/UEL), tendo sido aprovado conforme parecer985.064. Mediante a sua aprovação, foi verificado quais os professores responsáveis pelas 1asséries do Curso de Pedagogia para se estabelecer contato e agendar um horário que não comprometesse as suas aulas para a aplicação da escala de estratégia de aprendizagem. Após estabelecer o dia e hora, a escala foi aplicada pela pesquisadora em cada turma em separado, de forma coletiva.

\section{RESULTADOS E DISCUSSÃO}

Os dados serão apresentados, de acordo com 3 Fatores nas suas respectivas turmas (1000, 2000, 3000 e 4000) e, na sequência, por turno (matutino e noturno). Ao analisar os resultados do Fator 1 (Autorregulação Cognitiva e Metacognitiva) apresentados pelas diferentes turmas da $1^{\mathrm{a}}$ série, pode-se observar que os alunos da turma 1000 obtiveram as maiores frequências na opção "sempre"em relação as demais turmas nos seguintes itens:fazer anotações no texto ou em folhas à parte (74,1\%), verificar seus erros após receber uma nota de prova (74,1\%),anotar na agenda as coisas que tem para fazer (64,5\%),fazer algum esquema no papel para melhor entender as relações entre eles (48,3\%). A Turma 2000 apresentou as maiores frequências nas seguintes estratégias: rever as anotações feitas em sala de aula (62,9\%), procurar no dicionário o significado de palavras desconhecida (62,9\%), reler a matéria para entendê-la melhor (62,9\%). As maiores frequências apresentadas pela Turma 3000 em relação às estratégias de aprendizagem, foram: ler os textos indicados pelo professor (75\%), colar lembretes para recordar do que precisa fazer (55\%) e a turma 4000 apresentou a maior frequência para a estratégia de ler suas respostas novamente antes de entregar a prova (85\%).

Em relação às opções de respostas "raramente" e "nunca", as turmas 1000 , 2000 e 4000 não apresentaram nenhuma frequência alta, sendo que a turma 3000, para a opção de resposta "raramente" apresentou frequência alta na estratégia de 
elaborar perguntas e respostas sobre o assunto estudado (45\%).

Ao comparar as turmas por turno, pode-se observar que, as turmas do período noturno apresentaram as maiores frequências em mais estratégias de aprendizagem do que as turmas do período matutino em relação à opção de resposta "sempre", já na opção "raramente" e "nunca" não é possível fazer essa comparação, pois apenas a turma 3000 apresentou frequências.

Ao analisar as estratégias já descritas, segundo Dembo (2000 apud BORUCHOVITCH, 2001) é possível afirmar que um bom leitor é consciente do grau e da qualidade de sua compreensão e sabe o que fazer e como fazer quando não compreende.

Ao comparar os resultados obtidos no Fator 2 (Autorregulação dos Recursos Internos e Contextuais), em relação às turmas da $1^{\mathrm{a}}$ série, pode-se observar que os alunos da turma 1000 obtiveram as maiores frequências na opção de resposta "sempre", para as estratégias de aprendizagem: controlar sua ansiedade em situações de avaliação (32,4\%), administrar seu tempo de estudo (35,4\%), organizar seu ambiente de estudo (54,8\%), manter a calma diante de tarefas difíceis(38,7\%) e conseguir ir até o final de uma tarefa mesmo quando ela é difícil ou tediosa (48,3\%). Em relação à turma 2000, a maior frequência foi na estratégia de aprendizagem: planejar suas atividades de estudo (29,6\%). Na Turma 3000, a maior frequência observada foi na estratégia de separar todo o material necessário para a tarefa que irá realizar (80\%) e na turma 4000 foi observado que não houve nenhuma frequência alta nessa opção de resposta.

Ao comparar as turmas em relação à opção de resposta "raramente", pode-se observar que na turma 1000 as maiores frequências foram nas seguintes estratégias: administrar seu tempo de estudo (22,5\%) e distrair-se ou pensar em outra coisa quando está lendo, estudando ou fazendo os trabalhos (61,2\%). Na turma 2000 e 4000 não houve nenhuma frequência alta nessa opção de resposta, já na turma 3000 as maiores frequências foram observadas nas estratégias: controlar sua ansiedade em situações de avaliação (30\%) e manter a calma diante de tarefas difíceis (25\%) na opção "raramente".

Ao compararmos as turmas por turno pode-se observar que, as turmas do período noturno apresentaram as maiores frequências em mais estratégias de aprendizagem na opção de resposta "sempre", enquanto na opção "raramente", apenas uma turma do noturno e uma do matutino apresentaram frequências altas 


\section{nesta opção.}

Analisando as estratégias já citadas, para Boruchovitch (2001), monitorar o próprio processo de aprender é essencial ao sucesso de qualquer estudante, uma vez que os estudantes bem-sucedidos possuem a capacidade de monitoramento bem desenvolvido, são capazes de monitorar a compreensão, o uso de estratégias, o esforço e engajamento nas tarefas e em outras atividades. O monitoramento da compreensão implica que o indivíduo tenha a consciência do quanto ele está captando de um determinado conteúdo, também o controle diante das atividades difíceis e a atenção do que se está fazendo.

Em relação ao Fator 3 (Autorregulação Social) pode-se observar que os alunos das turmas 1000 e 2000 não apresentaram frequência alta na opção de resposta "sempre". Os alunos da Turma 3000 apresentaram as maiores frequências na opção "sempre" nas seguintes estratégias: pedir ajuda aos colegas em caso de dúvidas (70\%) e estudar em grupo (20\%). A turma 4000 apresentou a maior frequência na estratégia: discutir a matéria com os colegas para ver se entendeu (45\%).

Ao comparar os resultados da opção de resposta "raramente" e "nunca", observou-se que na opção "raramente", a turma 1000 apresentou as maiores frequências nas estratégias: estudar em grupo (35,4\%) e pedir para alguém tomar a matéria (45,1\%). Em relação à opção de resposta "nunca", a turma 2000 apresentou as maiores frequências nas estratégias: estudar em grupo $(22,2 \%)$ e pedir para alguém tomar a matéria (25,9\%). As turmas 3000 e 4000 não apresentaram nenhuma frequência alta nessas opções de respostas.

Ao comparar as turmas por turno, pode-se observar que as turmas do período matutino apresentaram as maiores frequências em relação à opção de resposta "sempre". Em relação à opção de resposta "raramente" e "nunca", pode-se observar que as turmas do período noturno apresentaram as maiores frequências, enquanto as turmas do período matutino não apresentaram frequências altas nessas opções de respostas.

Analisando as estratégias supracitadas, pode-se perceber que os alunos não fazem uso dessas estratégias com frequência.

No estudo de Góes e Alliprandini (2015) os resultados apontaram que a maioria dos participantes prefere tirar dúvidas usando livros, anotações e recursos que não envolvem o contato social, assim como na presente pesquisa, uma vez que nos itens relativos à estratégia de autorregulação social, os resultados apontaram que os 
alunos interagem pouco entre si quando precisam tirar dúvidas ou discutir a matéria.

\section{CONCLUSÃO}

No geral, os resultados evidenciaram um maior uso dasEstratégias de Autorregulação Cognitivas e Metacognitivas, seguidas pelas Estratégias de Autorregulação dos Recursos Internos e Contextuais e Autorregulação Social,o que merece especial atenção na promoção do uso destas estratégias.

Em relação à análise dos turnos, os resultados evidenciaram que no Fator $1 \mathrm{e}$ 2, as turmas do período noturno apresentaram as maiores frequências em relação àopção de resposta "sempre" e as turmas do período matutino, as maiores frequências para a opção "raramente" e "nunca". Já no Fator 3 os resultados evidenciaram um equilíbrio, pois as turmas do período matutino apresentaram as maiores frequências para a opção "sempre", enquanto as turmas do período noturno não apresentaram frequência alta em nenhuma estratégia.Porém, nas opções "raramente" e "nunca", as turmas do período noturno foram as que apresentaram as maiores frequências, enquanto as turmas do período matutino não apresentaram nenhuma frequência alta nessas opções de respostas.

Diante dos resultados da presente pesquisa, por se tratar de uma pesquisa realizada com futuros professores, evidencia-se a necessidade de se dar mais atenção a esse tema durante o curso para que os futuros professores possam ensinar as estratégias de aprendizagem adequadamente aos seus alunos, para que se tornem bem mais sucedidos.

Para que os alunos de fato desenvolvam ao longo do curso o aprender a aprender, torna-se necessário que haja uma reflexão e formação dosprofessores em exercício no que tange a promoção do uso das estratégias de aprendizagem. A partir dessa postura, os referidos futuros professores conseguirão usar, incentivar e instruir os seus alunos a aprenderem a aprender, possibilitando, consequentemente, uma continuidade desse ensino.

\section{REFERÊNCIAS}

ALMEIDA, L.S. Facilitar a aprendizagem: ajudar alunos a aprender a pensar. Psicol. Esc. Educ., v.6, n.2, p.155-165, 2002.

BORUCHOVITCH, E. Algumas estratégias de compreensão em leitura de alunos do ensino fundamental. Psicol. Esco. Educ. v.5, n.1, 2001. 
BORUCHOVITCH, E. Estratégias de aprendizagem e desempenho escolar: considerações para a prática educacional. Psicol. Reflex. Crit. v.12, n.2, p. 361-376, 1999.

FREIRE, L.G.L. Auto-regulação da aprendizagem. Ciênc. Cogn., v.14, n.2, 2009.

GÓES, N.M.; ALLIPRANDINI, P.M.Z. Estratégias autorregulatórias, cognitivas e comportamentais empregadas por estudantes de um curso de pedagogia ofertado a distância em função da faixa etária. Rev. COCAR, v.9, n.18, p.166-192, 2015.

SANTOS, A.A.A.; BORUCHOVITCH, E. Psychometric studies of the learning strategies scale for university students. Paidéia, n.60, p.19-27, 2015. 